\title{
Componentes do sistema de tratamento de esgoto com plantas
}

\author{
Fernando Ernesto Ucker, Rogério de Araújo Almeida, \\ Anna Paula Ferreira Batista Goldfeld Ucker, Pedro Daniel da Cunha Kemerich \\ Laboratório de Planejamento e Monitoramento Ambiental - LPMA/UFSM \\ Curso de Engenharia Ambiental da Universidade Federal de Santa Maria - UFSM/CESNORS
}

\section{Resumo}

O presente trabalho, de caráter teórico, tem por objetivo comentar sobre os principais componentes de um sistema de tratamento de esgoto com plantas, que são os substratos, microrganismos e plantas. Este tipo de tratamento torna-se a cada dia mais atrativo, por evidenciar um tratamento que simula os fenômenos que ocorrem espontaneamente na natureza, além de serem mais baratos e, as vezes, mais eficientes para a remoção de determinados parâmetros, do que os tratamentos convencionais. Este artigo vem a somar para que o sistema de tratamento de esgoto com plantas seja mais estudado no País. Atualmente, são poucos os Estados brasileiros que pesquisam as diversas variedades de plantas e substratos existentes.

Palavras-chave: microrganismos, substratos, tratamento de esgoto com planta

\begin{abstract}
This study of a theoretical, aims to review the main components of a system with sewage treatment plants, which are the substrates, microorganisms and plants. This type of treatment becomes increasingly more attractive for a treatment that simulates show the phenomena occurring spontaneously in nature, and are less expensive and sometimes more effective for removing certain parameters of the treatments conventional. This article comes to add to the system of sewage treatment plants to be studied further in the country currently, few Brazilian states researching the different varieties of plants and existing substrates.
\end{abstract}

Keywords: wetlands, microorganisms, substrates 


\section{INTRODUCC̃̃O}

Uma alternativa de minimização dos impactos ambientais causados pelos esgotos é o uso de Estações de Tratamento de Esgoto (ETEs), que possuem a principal função de, por meio de processos físicos, químicos e biológicos, remover os contaminantes presentes no esgoto, devolvendo ao meio ambiente um efluente em conformidade com os padrões exigidos pela legislação ambiental vigente.

Porém, apesar de serem conhecidos inúmeros sistemas para realizar o tratamento de esgoto, uma estação de tratamento nem sempre é viável economicamente. Esta realidade exige que novos sistemas sejam urgentemente estudados e implementados, a fim de obter-se uma tecnologia capaz de relacionar favoravelmente o custo/benefício, tanto para o meio ambiente quanto para a sociedade.

Entre as soluções mais atrativas encontradas evidenciam-se aqueles tratamentos que simulam os fenômenos que ocorrem espontaneamente na natureza, como os verificados nos brejos, em que espécies vegetais purificam as águas. O tratamento de efluentes pelo sistema de alagados construídos constitui uma opção reconhecida e recomendada, sendo efetivo na redução da matéria orgânica, na assimilação de nutrientes de plantas e retenção ou eliminação de substâncias tóxicas que, de outra maneira, seriam lançadas no meio ambiente (ARIAS; BRIX, 2003).

Neste sentido, um grande campo de pesquisas está se consolidando no país, o chamado sistema de tratamento de esgotos por alagados construídos, onde há a inserção de plantas que, com a ação conjunta de microrganismos e a interação com o substrato, realizam a degradação da matéria orgânica por meio da liberação de oxigênio por suas raízes, além da fixação de nutrientes por plantas e microrganismos.

O sistema de tratamento de alagados construídos, também conhecido como wetlands, zona de raízes, leitos cultivados, entre outros, possui vantagens promissoras que podem fazer com que esta técnica seja muito adotada, como um baixo custo de implantação e manutenção, pouco consumo de energia elétrica, além da produção de um efluente de boa qualidade.

Este trabalho, de caráter teórico, tem por objetivo explicar os componentes de um sistema de tratamento de esgoto com plantas.

\section{REVISÃO BIBLIOGRÁFICA}

\section{I Tratamento de Esgoto}

Segundo Kaick (2002), a falta de saneamento básico é a maior causa dos mais sérios problemas ambientais e de contaminação dos recursos hídricos. Para a autora, o esgoto doméstico é responsável por $90 \%$ dos lançamentos que contaminam os corpos d'água. Essa porcentagem ressalta a importância e a urgência do estudo e do desenvolvimento de tecnologias apropriadas para resolver o problema.

Uma dessas tecnologias, desenvolvidas para solucionar, ou diminuir, o problema de contaminação dos recursos hídricos, são os sistemas de tratamento de esgotos. Tais sistemas são responsáveis pela captação do esgoto gerado por uma determinada população. Segundo Sperling (2005), depois de captado o esgoto passa por uma estação de tratamento, em que processos, geralmente físicos, químicos e biológicos, o purificam, antes de dispô-lo no corpo receptor.

De acordo com Almeida (2005), a estação de tratamento de esgotos destina-se à depuração dos esgotos produzidos na cidade. As etapas e os processos de tratamento a serem selecionados são função dos fatores: tamanho da população, condições climáticas da região, área disponível para a estação, porte do corpo receptor, etc. Sperling (2005) acrescenta ainda fatores como: objetivos do tratamento, nível do tratamento e impacto ambiental do lançamento no corpo receptor.

Em grande parte das estações de tratamento de esgotos instaladas no Brasil, as etapas de tratamento terminam no nível secundário, ou seja, no tratamento biológico. Um dos principais fatores para que isto ocorra são os elevados valores financeiros para a instalação e operação de um sistema terciário, o qual geralmente exige alto consumo de eletricidade em processos como ozonização e radiação ultravioleta.

\subsection{Tratamento de esgotos com plantas}

De acordo com Zanella (2008), o tratamento de esgoto com plantas é um complexo arranjo de água, substrato, raízes dos vegetais e um grande conjunto de microrganismos que se inter-relacionam para melhoria da qualidade das águas. Nesses ecossistemas pode-se observar que as águas, ao passar pelo substrato, sofrem um processo de purificação por meio de alguns processos, como: filtração e precipitação química 
pelo contato da água com o meio suporte; retenção de material particulado suspenso; transformações químicas; predação e redução natural de organismos patogênicos, além da ação das plantas, que crescem e retiram nutrientes ao mesmo tempo em que o sistema radicular melhora as condições físico-químicas do substrato.

Brix (1993) relata que os tratamentos de esgoto com plantas representam uma tecnologia emergente que está se revelando como uma alternativa muito eficiente aos sistemas convencionais. Esses sistemas podem ser implementados no mesmo local em que o esgoto é produzido, podem ser operados por pessoas de baixo nível de escolaridade, têm baixo gasto energético e são mais flexíveis e menos susceptíveis a variações nas taxas de aplicação do esgoto. Sua principal desvantagem está na maior necessidade de área, o que segundo Almeida (2005), não é um fator muito limitante no Brasil, país de extensão continental, notadamente nas áreas mais afastadas dos grandes centros urbanos.

Esta tecnologia é utilizada devido às suas características de simplicidade de construção, operação e manutenção (HABERL, 1999). Arias e Brix (2003) destacam também a alta eficiência e o baixo custo de implantação, além de uma melhoria na qualidade ambiental, efeito paisagístico, criação e restauração de nichos ecológicos e uma grande produção de biomassa, que pode depois ser usada como alimento para animais e na produção de energia e de produtos artesanais, criando, assim, uma perspectiva de geração de renda.

Os chamados sistemas naturais de tratamento de esgotos se enquadram bem nos requisitos baixo custo e facilidade de operação do sistema, e se diferenciam dos sistemas convencionais em relação à fonte de energia utilizada. Estes sistemas naturais requerem a mesma quantidade de energia de input para degradar certa quantidade de contaminante, porém valem-se para isso de outras fontes de energia, como a radiação solar (KADLEC; KNIGHT, 1996).

Toniato et al. (2005) apresentam alguns nomes dados para esses sistemas, como: zona de raízes, wetlands, alagados construídos e leitos cultivados. Outros nomes utilizados para este tipo de tratamento são: trincheiras filtrantes, lagoas ou leito de macrófitas e FITO-ETARs (estações de tratamento de águas residuais através de plantas) (DIAS; PACHECO; SOUTINHO, 2000). Neste trabalho optou-se por utilizar o termo alagados construídos.

Valentim (1999) relata que o tratamento de esgoto em alagados construídos é o resultado da união entre os processos físicos, químicos e biológicos que ocorrem por causa do filtro físico, das comunidades bacterianas e das macrófitas. As bactérias são fundamentais para o tratamento do efluente, uma vez que são responsáveis pela degradação da matéria orgânica, por meio de processos anaeróbios, anóxicos e aeróbios. As condições aeróbias são conseguidas principalmente devido ao fornecimento de oxigênio pelas raízes das macrófitas.

\subsection{Componentes do Sistema de Tratamento de Esgoto com Plantas}

\section{Substrato}

De acordo com Silva (2007), o substrato usado no sistema alagados construídos tem dupla função: filtração no decorrer do processo de tratamento de águas residuárias e suporte para o enraizamento das plantas.

Os substratos mais utilizados nos sistemas instalados tanto na Europa quanto nos Estados Unidos são a brita e a areia lavada (Figura 1), que apesar de ser um dos itens de maior custo na implantação, se justifica por permitir um fluxo regular e aumentar o período de tempo entre as limpezas ou substituição do substrato (USEPA, 1999). Estes dois materiais são também os mais utilizados nos sistemas implantados no Brasil (VALENTIM, 2003).

As primeiras experiências desenvolvidas na Alemanha utilizavam como meio suporte o próprio solo do local onde o sistema era instalado. Porém, os sistemas baseados em solo apresentaram a formação de escoamento superficial, devido à baixa condutividade hidráulica da maioria dos solos naturais, impedindo o contato do esgoto com a rizosfera (VYMAZAL et al., 1998). Este problema foi logo solucionado com a utilização de meiossuporte mais porosos, como a brita de diferentes granulometrias, além da areia (ZANELLA, 2008).

A utilização de outros materiais, também chamados alternativos, começou a ser testada. Roston e Collaço (2003) utilizaram pneu picado como meio suporte em alagados de fluxo sub-superficial para pós-tratamento de efluentes domésticos. Os resultados mostraram que há potencialidade no uso de pneu picado em substituição aos materiais convencionalmente utilizados como meio suporte.

A seleção do meio suporte está diretamente relacionada com o tipo de escoamento e a remoção de contaminantes desejada. Não se deve utilizar um meio suporte que contenha alto teor de argila porque os contaminantes ao invés de serem degra- 


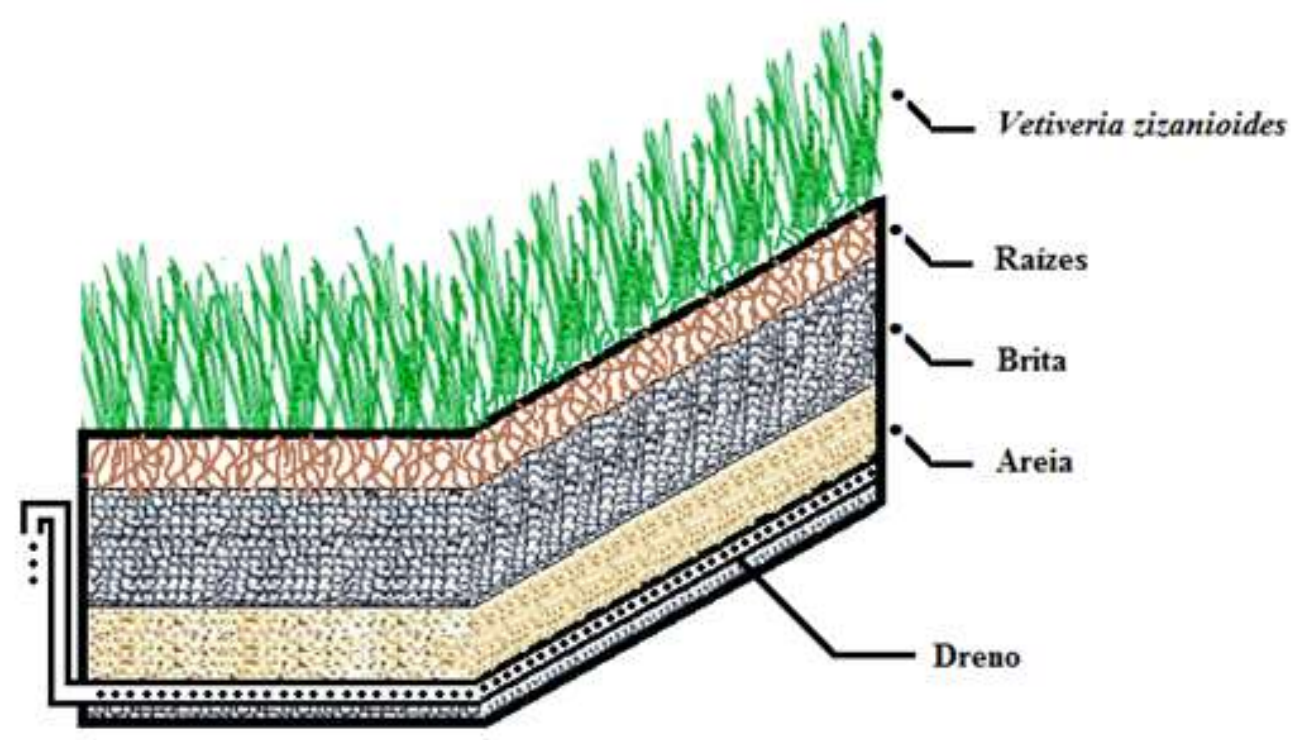

Figura 1 - Representação esquemática da distribuição das camadas de substrato no sistema alagado construído de fluxo vertical descendente.

dados pelos microrganismos tenderão a acumularse no substrato e após saturação serão novamente liberados para o efluente (DUARTE, 2002). Outro problema é a possível colmatação do substrato.

Para evitar este tipo de problema, uma solução pode ser a adição de sistemas de pré-tratamentos ao sistema de tratamento de esgoto com plantas. O pré-tratamento tem função de decantação e/ou filtração, ajudando a evitar a colmatação precoce, uma vez que os teores de sólidos do esgoto são reduzidos consideravelmente após passar por estas unidades. Assim, segundo Pitaluga (2011), a ação de pré-tratar ajuda na eficiência e no tempo de vida funcional do leito com plantas, o que também se consegue pela utilização de substratos de maior granulometria.

\section{Plantas}

Além do papel nos ecossistemas e do efeito estético, as plantas podem ser utilizadas para os mais diversos fins. São úteis para a alimentação, como é o caso do arroz que cresce em regiões alagadas, e de algumas espécies marinhas tradicionais na cultura japonesa, além de servirem para a construção de moradias. Para o tratamento de esgotos, várias espécies vegetais podem e são utilizadas (ZANELLA, 2008).

As plantas que caracterizam esta tecnologia de tratamento, além de a valorizarem esteticamente, provaram desempenhar papeis fundamentais em todo o processo depurativo. As partes aéreas das plantas (folhas e caules), por exemplo, funcionam essencialmente como armazém de nutrientes. No entanto, outras funções são-lhes atribuídas, como: capacidade de atenuação da luz solar (reduzir o crescimento de algas) e redução da velocidade do vento (estabilizar a superfície do leito) (De VOS, 1997).

As plantas presentes nos alagados também requerem nutrientes para seu crescimento e reprodução, sendo a absorção de tais nutrientes realizada principalmente pelas raízes. Verifica-se que uma elevada quantidade destes nutrientes é assimilada e convertida em biomassa, podendo ser posteriormente colhida. Caso não ocorra a colheita, os nutrientes que foram incorporados à planta retornam à água pelos processos de decomposição das espécies vegetais. A vegetação também pode suportar uma diversa vida selvagem, sendo habitat para pássaros, répteis e anfíbios (BRIX, 1994; BRIX, 1997; ABRANTES, 2009).

Hostins, Ucker e Almeida (2011) avaliaram o potencial do lírio-do-brejo (Hedychium coronarium J. König) na remoção de nutrientes do esgoto sanitário em um sistema de tratamento do tipo alagados construídos, analisando sua composição química e a produção de matéria seca, em três diferentes substratos (brita \# 0, brita \# 1 e areia lavada). Os autores concluíram que, além de ser uma planta capaz de remover boas quantidades de nutrientes do solo, como fósforo e nitrogênio, é acumuladora do micronutriente ferro $(\mathrm{Fe})$, tendo removido do sistema até $675 \mathrm{mg}$ de ferro por $\mathrm{kg}$ de matéria seca produzida. Os resultados obtidos mostram que as plantas podadas na manutenção das estações de tratamento de esgoto podem ser 
utilizadas como fertilizantes de solos.

Outra função muito importante das plantas deste sistema é a transferência de oxigênio através da rizosfera, sendo que este contexto será discutido em um tópico específico a seguir. O Quadro 1 sintetiza as diversas funções das plantas, de acordo suas partes constituintes.

No Brasil há uma grande riqueza de espécies vegetais com potencial para o tratamento de esgotos, e a maioria das espécies tem boa tolerância a períodos limitados de seca, e vive perfeitamente em locais alagados ou inundados (SILVA, 2007). Fundamentalmente, a vegetação utilizada para o tratamento de esgotos deve tolerar áreas permanentemente saturadas ou submersas e o fluxo constante de contaminantes dos mais diversos tipos e concentrações.

Para Zanella (2008), devem ser preferidas espécies nativas locais, devido à maior facilidade de adaptação e crescimento nas condições climáticas existentes. Espécies exóticas podem ser usadas somente se já foram introduzidas na região ou se não forem suficientemente competitivas para que se tornem uma praga caso ocorra uma fuga do sistema de tratamento.

\section{Microrganismos}

A maioria dos alagados é dominada por uma variedade de microrganismos, especialmente bactérias e fungos. Estes organismos, com a sua diversidade genética e adaptação funcional, são capazes de usar os constituintes das águas contaminadas para seu crescimento e reprodução. Ao usar os constituintes, estes organismos mediam transformações químicas, físicas e biológicas dos contaminantes e modificam a qualidade da água (MANSOR, 1998).

Segundo Sauer e Kimber (2001), os microrganismos decompõem a matéria orgânica, ativam processos biogeoquímicos e atuam sobre outros microrganismos presentes nas águas residuárias. Os microrganismos, por meio da produção de enzimas e catalizadores, promovem a maioria das transformações químicas ocorridas nos leitos dos alagados construídos (KADLEC; KNIGHT, 1996).

Para Kaick (2002), nas raízes das plantas fixam-se bactérias que recebem oxigênio e nitrogênio conduzidos pelas plantas do caule até as raízes, por meio dos aerênquimas. Em troca, as bactérias decompõem a matéria orgânica, transformando-a em nutrientes que são repassados às plantas. Nos sistemas convencionais de tratamento de esgoto, o processo de decomposição anaeróbia da matéria orgânica libera gases que produzem mau cheiro. No caso dos sistemas de tratamento por plantas, o mau cheiro é evitado porque as próprias raízes (além da liberação de oxigênio) funcionam como um filtro, eliminando-o.

Hussar (2001) afirma que o principal fator

Quadro 1 - Principais funções das partes das plantas no sistema de tratamento de esgoto do tipo alagados construídos (BRIX, 1997; ABRANTES, 2009).

\begin{tabular}{|c|c|}
\hline Partes da planta & Funções \\
\hline \multirow{4}{*}{ Parte aérea } & Atenuação de luz $\rightarrow$ reduz o crescimento de fitoplâncton \\
\hline & Redução da velocidade do vento \\
\hline & Efeito estético \\
\hline & Armazenamento de nutrientes \\
\hline \multirow{5}{*}{ Tecidos submersos } & Filtragem \\
\hline & Redução da velocidade da corrente de água \\
\hline & Superfície para formação de biofilmes \\
\hline & Consumo de nutrientes \\
\hline & Excreção de oxigênio fotossintético \\
\hline \multirow{5}{*}{ Raízes e Rizomas nos sedimentos } & Bio-Drenagem $\rightarrow$ inviabiliza a colmatação do substrato \\
\hline & $\begin{array}{c}\text { Liberação de oxigênio } \rightarrow \begin{array}{l}\text { favorece a degradação da matéria } \\
\text { orgânica }\end{array} \\
\end{array}$ \\
\hline & Absorção de nutrientes \\
\hline & Liberação de antibióticos \\
\hline & Habitat de micro e macro biotas \\
\hline
\end{tabular}


de consumo de oxigênio no sistema se dá por meio da oxidação da matéria orgânica, devido à respiração dos microrganismos decompositores. $\mathrm{Na}$ presença de oxigênio, as bactérias convertem a matéria orgânica a compostos simples, como água e gás carbono.

As partes da planta que ficam submersas na água e no solo (parte dos caules, raízes e rizomas) desempenham as mais variadas ações sobre todo o sistema, onde provavelmente as mais importantes são: servir de suporte de fixação para os microrganismos envolvidos em todo o processo biológico e fornecer oxigênio ao sistema de forma a promover a biodegradação (De VOS, 1997).

De acordo com Sperling (1996), as bactérias são os microrganismos mais importantes na decomposição da matéria orgânica e reciclagem de nutrientes, e podem apresentar-se isoladamente ou em colônias. No sistema de alagados construídos, há a formação de biofilme, que fica aderido ao substrato e às raízes das plantas. Este biofilme é composto por uma série de microrganismos, os quais ajudam na degradação da matéria orgânica e na transformação da série nitrogenada (nitrificação e desnitrificação). O oxigênio requerido para isto é fornecido pelas raízes das plantas e pela difusão do ar atmosférico (SEZERINO, 2006).

Para Hussar (2001), tanto as bactérias quanto os fungos têm uma relação simbiótica com o meio em que vivem. Os primeiros estão em simbiose com as raízes e partes submersas. A segunda classe de organismos, mantém relação de simbiose com algumas espécies de algas (líquens) e plantas mais evoluídas (micorrizas), aumentando a eficiência dos hospedeiros na absorção de nutrientes da água, do ar e do meio suporte.

Um fator muito importante e que afeta diretamente os microrganismos, e consequentemente a velocidade de decomposição da matéria orgânica, é a temperatura. De acordo com Sperling (1996), em geral os esgotos possuem temperatura um pouco mais elevadas em comparação com a água de abastecimento. Temperaturas mais elevadas aumentam a ação dos microrganismos, aumentando assim a eficiência na decomposição da matéria orgânica.

\section{CONCLUSÕES}

Este artigo de caráter teórico vem a somar para que o sistema de tratamento de esgoto com plantas seja mais estudado no País. Atualmente, são poucos os Estados brasileiros que pesquisam as diversas variedades de plantas e substratos existentes.

\section{REFERÊNCIAS}

ABRANTES, L. L. M. Tratamento de esgoto sanitário em sistemas alagados construídos utilizando Typha angustifolia e Phragmites australis. Dissertação (Mestrado em Engenharia do Meio Ambiente) - Escola de Engenharia Civil, Universidade Federal de Goiás, Goiânia, 2009. 140 p.

ALMEIDA, R. A. Substratos e plantas no tratamento de esgoto por zona de raízes. Tese (Doutorado em Agronomia: Produção Vegetal)-Escola de Agronomia e Engenharia de Alimentos, Universidade Federal de Goiás, Goiânia, 2005. 108 p.

ARIAS, C. A; BRIX, H. Humedales artificiales para el tratamiento de águas residuales. Revista Ciência e Ingeniería Neogranadina, Bogotá, Colombia. v.13, p. 17-24, 2003.

BRIX, H. Wastewater treatment in constructed wetlands: system design, removal processes, and treatment performance. In: MOSHIRI, G.A. (Ed.) Constructed wetlands for water quality improvement. Boca Raton: CRC Press, p. 9-23, 1993.

BRIX, H. Use of constructed wetlands in water pollution control: historical development, present status, and future perspectives. Water Science and Technology, v. 30, n. 8, p. 209-223, 1994.

BRIX, H. Do macrophytes play a role in constructed treatment wetlands? Water Science and Technology, v.35, n.5, p.11-17, 1997.

DE VOS, J. Secagem e tratamento biológico de lodos em leitos de macrófitas. Portugal, 1997.

DIAS, V.; PACHECO, P. M.; SOUTINHO, E. A. FITO-ETAR'S: Mecanismos de depuração e papel das plantas. In: $5^{\circ}$ congresso da água: a água e o desenvolvimento sustentável, desafios para o novo século, 2000, Lisboa. Resumos... Lisboa: APRH, 2000. p. 01-14. Disponível em: <http://www.aprh. pt/congressoagua2000/comunic/108.pdf > . Acesso em: 24 fev. 2011.

DUARTE, S. Estudo das potencialidades das zonas húmidas Artificiais no tratamento de efluentes aquícolas. Monografia de final de curso, Departa- 
mento de Engenharia Biológica e Química, Licenciatura em Engenharia do Ambiente, Portugal, Instituto Superior Técnico, Universidade de Lisboa. 2002.

HABERL, R. Constructed wetlands: a chance to solve wastewater problems in developing countries. Water Science and Technology, v. 40, n. 3, p.1-17, 1999.

KADLEC, R. H.; KNIGHT, R. L. Treatment Wetlands. Boca Raton, Florida: Lewis Publishers, 1996. $893 \mathrm{p}$.

KAICK, T. S. V. Estação de tratamento de esgoto por meio de zona de raízes: uma proposta de tecnologia apropriada para saneamento básico no litoral do Paraná. Curitiba, PR: 2002. Originalmente apresentada como dissertação de mestrado, Programa de Pós-graduação em Tecnologia - Centro Federal de Educação Tecnológica do Paraná, 2002. 116 p.

HOSTINS, D. C.; UCKER, F. E.; ALMEIDA, R. A. Potencial do lírio-do-brejo (Hedychium coronarium j. Konig) na remoção de nutrientes do esgoto sanitário em um sistema de tratamento do tipo zona de raízes. In: XIX Seminário de Iniciação Científica / VIII Congresso de Pesquisa, Ensino e Extensão da Universidade Federal de Goiás, 2011, Goiânia. Anais... 63를 Reunião Anual da SBPC, Goiânia - GO, 2011.

HUSSAR, G. J. Avaliação do desempenho de leitos cultivados no tratamento de águas residuárias de suinocultura. Campinas, SP: 2001. Originalmente apresentada como dissertação de mestrado, Faculdade de Engenharia Agrícola - Universidade Estadual de Campinas, 2001. 118 p.

MANSOR, M. T. C. Uso de leito de macrófitas no tratamento de águas residuárias. Campinas, SP: 1998. Originalmente apresentada como dissertação de mestrado, Faculdade de Engenharia Agrícola Universidade Estadual de Campinas, 1998. 106 p.

PITALUGA, D. P. S. Avaliação de diferentes substratos no tratamento de esgoto sanitário por zona de raízes. Dissertação (Mestrado em Engenharia do Meio Ambiente)-Escola de Engenharia Civil, Universidade Federal de Goiás, Goiânia, 2011. 133 p.

SAUER, P. A.; KIMBER, A. Technical assessment of constructed wetlands for wastewater treatment in Iowa. IOWA Associate of Municipal Utilities. United States. 2001.
SEZERINO, P. H. Potencialidade dos filtros plantados com macrófitas (constructed wetlands) no pós-tratamento de lagoas de estabilização sob condições de clima subtropical. Florianópolis, SC: 2006. Originalmente apresentada como tese de doutorado, Programa de Pós Graduação em Engenharia Ambiental, Universidade Federal de Santa Catarina, 2006. $171 \mathrm{p}$.

SILVA, S. C. Wetlands construídos de fluxo vertical com meio suporte de solo natural modificado no tratamento de esgotos domésticos. Brasília, DF: Universidade de Brasília. Originalmente apresentada como tese de doutorado, Universidade de Brasília UnB, 2007. 231 p.

SPERLING, M. von. Introdução à qualidade das águas e ao tratamento de esgotos. Princípios do Tratamento Biológico de águas residuárias. 2. ed. Belo Horizonte: Departamento de Engenharia Sanitária e Ambiental, Universidade Federal de Minas Gerais, 1996. 1v.

TONIATO, J. V; ROQUE, O. C. C.; KACZALA, F.; NASCIMENTO, V. B.; ROQUE, D. C. Avaliação de um wetland construído no tratamento de efluentes sépticos. In: CONGRESSO DE ENGENHARIA SANITÁRIA E AMBIENTAL, 23., 2005, Campo Grande, MS. Resumos... Campo Grande, MS: ABES, 2005. ref. II-351.

USEPA - U. S. Environmental Protection Agency. Constructed wetlands treatments of municipal wastewaters. EPA/625/r-99/010, Cincinnati, Ohio, 1999. $152 \mathrm{p}$.

VALENTIM, M. A. A. Uso de leitos cultivados no tratamento de tanque séptico modificado. Campinas, SP: 1999. Originalmente apresentada como dissertação de mestrado, Faculdade de Engenharia Agrícola - UNICAMP, 1999. 119 p.

VYMAZAL, J.; BRIX, H.; COOPER, P. F.; HABERL, R.; PERFLER, R.; LABER, J. Removal mechanisms and types of constructed wetlands. In: VYMAZAL, J.; BRIX, H.; COOPER, P. F.; GREEN, M. B.; HABERL, R. (Ed.) Constructed wetlands for wastewater treatment in Europe. Leiden, The Netherlands: Backhuys Publishers, 1998. p. 17-66.

ZANELLA, L. Plantas ornamentais no pós-tratamento de efluentes sanitários: Wetlands-construídos utilizando brita e bambu como suporte. 
Campinas, SP: Universidade Estadual de Campinas, 2008. Originalmente apresentada como tese de doutorado, Universidade Estadual de Campinas - UNICAMP, 2008. 219 p. 